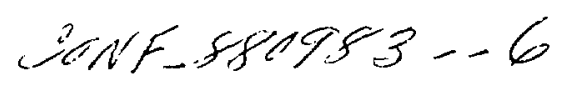

\title{
POLARIZED ION SOURCE DEVELOPMENT AT BROORHAVEN*
}

J.G. Alessi, B. DeVito, A. Hershcovitch, A. Kponou, C.R. Meitzler AGS Department, Brookhaven National Laboratory, Upton, NY 11973

INTRODUCTION

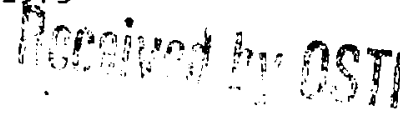

The present AGS polarized $\mathrm{H}^{-}$source employs a ground state

NOV 091988 atomic beam source and $\mathrm{Cs}^{\circ}$ charge exchange ionizer. It produces 30-40 $\mu \mathrm{A}$ of t- at 75-80\% polarization, in $500 \mu_{\mathrm{s}}$ pulses, $0.5 \mathrm{~Hz}$. Up to $60 \mu \mathrm{A}$ has at times been produced when the cesium beam is performing optimally. Work in progress to produce a higher intensity $\mathrm{H}^{-}$source includes cooling of the $\mathrm{H}^{\circ}$ beam to $6 \mathrm{~K}$ and ionization of the polarized atoms via charge exchange with $D^{-}$. Experiments to test the possibility of spin selection and focusing of $\mathrm{H}^{\circ}$ using a superconducting solenoid have beon completed, and have led us back to the more conventional approach of sextupoles.

\section{COLD ATOMIC BEAM}

We have been successful in our attempt to produce a high flux, 10 velocity $H^{\circ}$ beam by passage of the atoms through a $6 \mathrm{~K}$ copper accommodator saction at the exit of the rf dissociator. At $6 \mathrm{~K}$, time-of-flight measurements of the velocity distribution showed that the beam had a most probable velocity of $680 \mathrm{~m} / \mathrm{s}$, a FWHM of approximately $200 \mathrm{~m} / \mathrm{s}$, and a forward flux of $9.4 \times 10^{18}$ $\mathrm{H}^{\circ} / \mathrm{sr} / \mathrm{s}$. Complete details of the setup and experimental results have been given. 1 Subsequently, the atomic beam stage was further improved, and it is shown schematically in Figure 1 . It differs from the setup in Ref. 1 in several ways. The volume of the pyrex dissociator was reduced, allowing us to operate with a higher $r f$ power density into the dissociator (using the same power supply). The exit of the dissociator tube is cooled via a liquid nitrogen cooled copper clamp around the outside of the pyrex. Following this, there is a $0.3 \mathrm{~mm}$ gap, and then the liquid helium cooled copper accommodator. The teflon "transition" section between the dissociator and accommodator, used in the original design, has been eliminated. The accommodator channel now has a $15 \mathrm{~mm}$ long, 3 mo diameter nearly straight section, followed by a $15 \mathrm{~mm}$ long section which tapers out to a final diameter of $10 \mathrm{~mm}$. This followed from a suggestion of $T$. Nilnikosk1, ${ }^{2}$ and is based on the desire to keep the $\mathrm{H}^{\circ}$ density in the accommodator below the point where one begins to lose significant flux due to three-body recombination. The flare is an attempt to keep the atom density constant while the $H^{\circ}$ velocity is decreasing. Finally, the initial atomic beam source had a skimmer which was coated with

*Work performed under the auspices of the U.S. Department of Energy. 
charcoal and cooled to $<4 \mathrm{k}$, provlding cryopumping in a very critical region. In the new source, the skimmer was eliminated completely, and there is instead a stack of 10 cryopanels ( $<4 \mathrm{X}$ ) immediately following the accommodator. This is very effective in keeping the pressure outside the accommodator low.

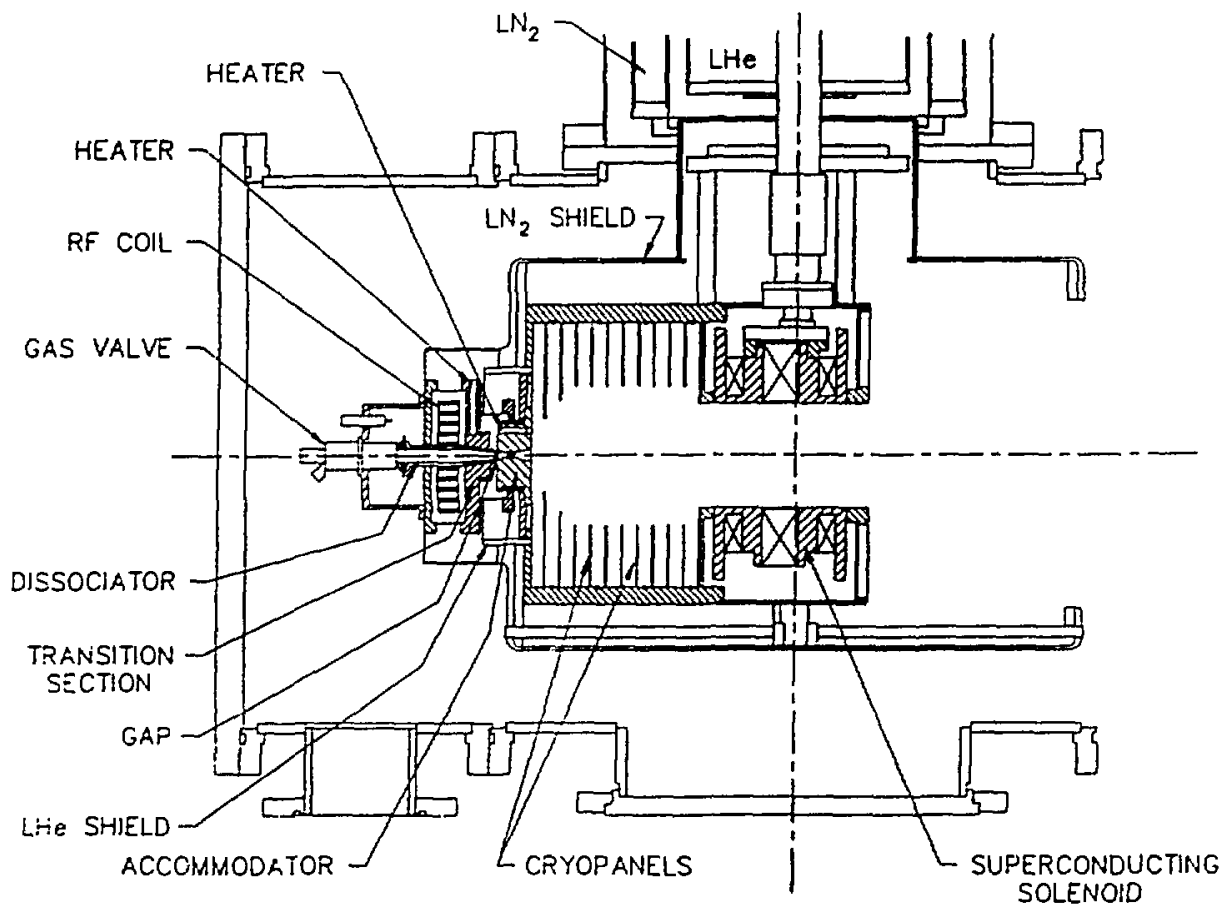

Figure 1. Schematic of the cold atomic beam and superconducting solenoid.

With this new atomic beam stage, and an accommodator temperature of $6 \mathrm{~K}$, an $\mathrm{H}^{\circ}$ density of $6 \times 10^{11} / \mathrm{cm}^{3}$ was measured $90.5 \mathrm{~cm}$ away. This density, measured via a quadrupole mass spectrometer and without any focusing of the atoms, was an improvement by a factor of 30 over the density measured with the atomic beam in Ref. 1. Velocity measurements could not be made in the new configuration. If one assumes that the most probable velocity is still $680 \mathrm{~m} / \mathrm{s}$, the forward flux from the new atomic beam is $3 \mathrm{x}$ $10^{20} \mathrm{H}^{\circ} / \mathrm{sr} / \mathrm{s}$ (a higher velocity would imply an even higher flux). As will be discussed in the next section, this atomic beam may be too intense to be used effectively for the production of polarized $\mathrm{H}^{\circ}$ atoms. 


\section{SPIN SELECTION AND FOCUSING}

The use of a type of superconducting solenold for focusing of $H^{\circ}$ atoms was proposed by $T$. Niinikoski (CERN), and is described in Ref. 3. With the high fields obcainable in such a coil, one could hopefully bulld a magnet having a sultable field gradient over a larger aperture than is possible in a conventional sextupole system. In collaboration with Ninikoski, such a solenold was built and tested. The solenoil consists of three colls connected in series, with the current in the outer two (2100 turns in each coil), counter to the current in the middle coil (4600 turns). This gives a high field at the inner dlameter of the coils and a weak field on axis, i.e., a larger magnetic fleld gradient, required for focusing of atoras. The three-coil system had an 1.d. of $9.4 \mathrm{~cm}$ and an overall length of $10 \mathrm{~cm}$. A field of $5.2 \mathrm{~T}$ was obtained at the coil i.d., at a current of 107 A. Field maps generated with the POISSON program for our geometry showed a disadvantage of the solenoid in that the gradient was very nonlinear (weak on axis), and because of this, track-tracing calculations of the $\mathrm{H}^{\circ}$ beam through the solenoid showed large aberrations in the focusing. First tests of the solenoid with the $\mathrm{H}^{\circ}$ beam, as shown in Figure 1, actually showed a slight decrease in the $\mathrm{H}^{\circ}$ density, measured $65 \mathrm{~cm}$ away from the coil exit, when the solenoid was energized. Several runs were then made in which the accomodator diameter was reduced, in order to decrease the $\mathrm{H}^{\circ}$ density (to see If $\mathrm{H}^{\circ}-\mathrm{H}^{\circ}$ scattering was the problem). Figure 2 shows the "focusing factor" (the ratio of the $\mathrm{H}^{\circ}$ density measured $65 \mathrm{~cm}$ from the solenoid with $B=4.38 \mathrm{~T}$ to the density with $B=0$ ), versus the density at $B=0$. Solenoid focusing was observed at lower densities, but fell off as the density was increased. We feel that this fall off is indeed a result of $\mathrm{H}^{\circ}-\mathrm{H}^{\circ}$ scattering, and there is a preliminary indication that at low temperatures this scattering cross section could be as large as $10^{-14} \mathrm{~cm}^{2}$. The fact that there is an upper density limit for magnetic spin selection, beyond which the mean free path for $\mathrm{H}^{\circ}$ atom scattering becones so small as to prevent the separation of the atoms of opposite electron spins, was previously considered. ${ }^{4}$ With the solenoid, the situation is made worse because the defocused atoms hitting the inner bore of the solenoid (at $4 \mathrm{k}$ ) do not readily recombine and get pumped away, but rather scatter off the solenoid, raising the local $\mathrm{H}^{\circ}$ density even further. Also, the solenoid gradient is higher at larger radil, so most of the focusing/defocusing occurs in the region near the walls.

Figure 3 shows $H^{\circ}$ profiles measured $22 \mathrm{~cm}$ from the solenoid exit for various solenoid currents. These were taken at a low density, and do demonstrate qualitatively the expected focusing. The measurements were made by scanning the beam with a $1 \mathrm{~mm} \times 1 \mathrm{~mm}$ thermoflake $\mathrm{H}^{\circ}$ detector. 5 The detector signal was normalized at $B=0, r=0$ to a mass spectrometer reading taken further downstream, assuming a $1 / \mathrm{r}^{2}$ falloff in density as one moves away from 


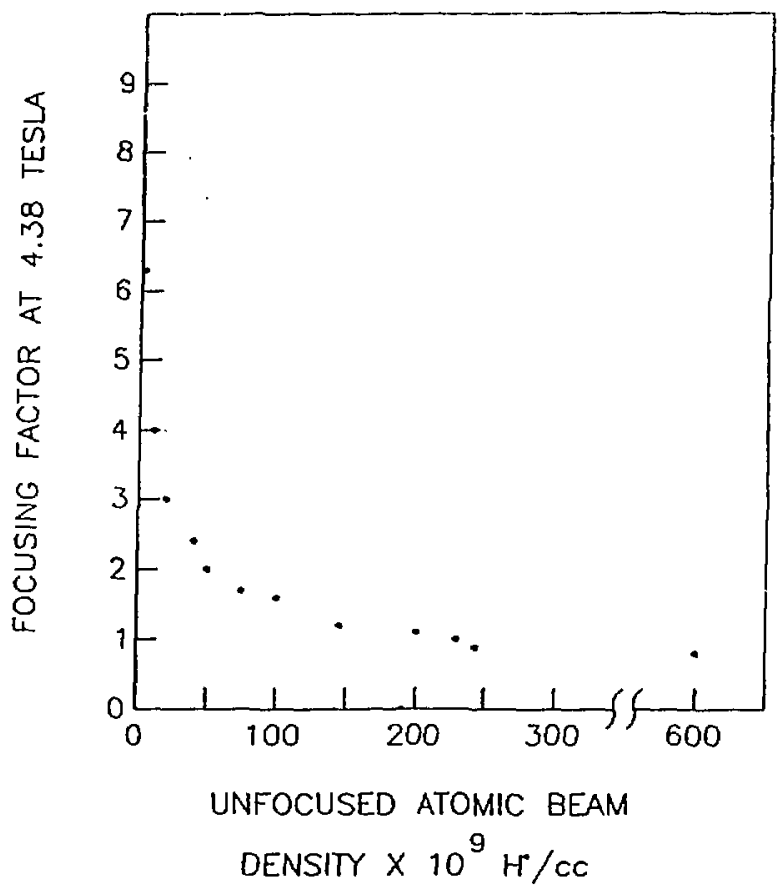

Figure 2. Variation of the focusing factor (ratio of $\mathrm{H}^{\circ}$ density at $\mathrm{B}=4.38 \mathrm{~T}$ to density at $\mathrm{B}=0$ ) vs. $H^{\circ}$ density at $B=0$.

the accommodator. The largest focusing effect observed, when the solenoid was at its maximum field of $5.1 \mathrm{~T}$ and at $10 \mathrm{w} \mathrm{H}^{\circ}$ density, was only a factor of 10 increase in $\mathrm{H}^{\circ}$ density over the $\mathrm{B}=0$ value. This relatively low value is probably indicative of the problem of the aberrations in the focusing. The alternative of focusing with a sextupole is now being pursued. Track-tracing calculations have shown that one can form a much better focused beam with the sextupole. These track-tracing calculations, however, neglect gas scattering effects which appear to be quite important at our high densities and low velocity. We will attempt to make the sextupole as open as possible so that the defocused atoms will not interfere with the primary beam. 


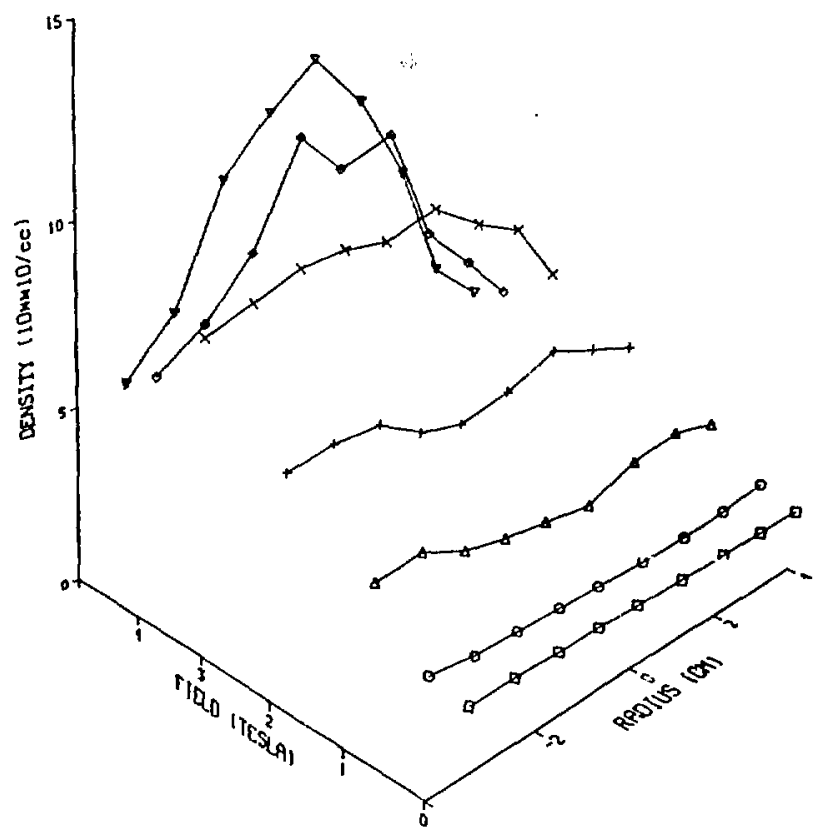

Figure 3. $H^{\circ}$ rensity proflles vs. solenold fleld, measured $22 \mathrm{~cm}$ from the solenold extt, taken at a low $\mathrm{H}^{\circ}$ density.

\section{RING MAGNETRON IONIZER}

In the ring magnetron lonizer, $H^{\circ}$ atoms ace ionized via charge exchange with $D^{-}$lons produced in a magnetron surfaceplasma source. Detalls of this compact, large acceptance tonfzer (approximately $2 \mathrm{~cm}$ long by 2 cin diameter lonization region) are given in Ref. 6. In Initlal tests of the innizer, $500 \mu \mathrm{A}$ of $\mathrm{H}^{-}$ was produced by charge exchange, with an estimated $H^{\circ}$ density in the lonization region of $10^{12} \mathrm{~cm}^{-3}$ (unpolarized). The ionizer was then installed in place of an electron bombardment iontzer on a polarized atomlc beam source. The beam ia extracted at $10 \mathrm{keV}$, and transported through two Elnzel lenses, a Wien filter for mass selectton, and a polarineter chamber, before reaching the Faraday cup $157 \mathrm{~cm}$ from the fonizer. The present performance is $50 \mu \mathrm{A}$ of $\mathrm{H}^{-}$extracted with an $\mathrm{H}^{\circ}$ density (unpolarized) in the lonizer of 3 $x \cdot 10^{11} \mathrm{~cm}^{-3}$. This $H^{\circ}$ density was determined by measuring the density downstrean of the tonizer with a quadrupole mass spectroineter, and the ionizer of $f$, and then assuming $a 1 / c^{2}$ fallof $f$ 
with distance from the dissoclator (there were no sextupoles). This efficiency is now approximately the same as the Cs ionizer on PONI-1, but less than that measured on the test stand. The most critical factor affecting the efficiency of the lonizer seems to be the high $D_{2}$ pressure in the lonizer region. The purping of $D_{2}$ from the ionizer is presently not very good due to poor conductances in the vicinity of the magnetron. From measurements of the $H^{\circ}$ density downstream of the ionizer with and without the Ionizer $D_{2}$ gas pulsing, we estimate a $D_{2}$ target thickness to the $\mathrm{H}^{\circ}$ bean of $\mathrm{nl}=5.4 \times 10^{14} / \mathrm{cm}^{2}$. We are planning a redesign of the magnetron to decrease the $\mathrm{D}_{2}$ pressure. Experiments with a polarized beal, to test for any depolarization, are also planned.

\section{CONCLUSIONS}

The performance of the $6 \mathrm{~K} \mathrm{H}^{\circ}$ beam source has exceeded expectations. $H^{\circ}$ gas scattering and aberrations seem to be problems in the superconducting solenoid, so we will be testing a permanent magnet sextupole for spin selection. The resultant $\mathrm{H}^{\circ}$ density one will obtain at the ionizer is difficult to estimate, since it may still be limited by $\mathrm{H}^{\circ}-\mathrm{H}^{\circ}$ scattering in the spin selection region. The polarized atomic beam will then be combined with an rf transition unit and the ring magnetron iontzer, and if $\mathrm{H}^{-}$intensities of at least several hundred microamperes are obtained, we will make the improvements necessary to turn this into an operational source for the AGS.

\section{REFERENCES}

1. A. Hershcovitch, A. Kponou, and T.0. Niinikoski, Rev. Sci. Instrum. 58, 547 (1987).

2. T.0. Nilnikoski, private communtcation.

3. M. Ellila, T.O. Nitinikoski, and S. Penttilla, Nucl. Instrum. Meth. B14, 521 (1986).

4. T.0. Niinikoski and A. Hershcovitch, Helv. Phys. Acta 59, 596 (1986).

5. K.C. Harvey and C. Fehrenback, Jr., Rev. Sci. Instrum. 59, 1117 (1983).

6. J.G. Alessi, Helv. Phys. Acta 59, 549 (1986).

\section{DISCLAIMER}

This report was prepared as an account of work sponsored by an agency of the United States Government. Neither the United States Government nor any agency thereof, nor any of their employees, makes any warranty, express or implied, or assumes any legal liability or responsibility for the accuracy, completeness, or usefulness of any information, apparatus, product, or process disclosed, or represents that its use would not infringe privately owned rights. Reference herein to any specific commercial product, process, or service by trade name, trademark, manufacturer, or otherwise does not necessarily constitute or imply its endorsement, recommendation, or favoring by the United States Government or any agency thereof. The views and opinions of authors expressed herein do not necessarily state or reflect those of the United States Government or any agency thereof. 